\title{
ASPECTOS DA FORMAÇÃO DO PROFESSOR DE ENSINO SUPERIOR DE CIÊNCIAS CONTÁBEIS: UMA ANÁLISE DOS PROGRAMAS DE PÓS-GRADUAÇÃO
}

\author{
ASPECTS OF ACCOUNTING TEACHERS' EDUCATION AT COLLEGE LEVEL: \\ AN ANALYSIS OF GRADUATE PROGRAMS
}

\author{
MAIRA ASSAF ANDERE \\ Professora Assistente do Curso de Ciências Contábeis \\ das Faculdades Integradas Fafibe - Bebedouro \\ E-mail:maandere@yahoo.com.br
}

\author{
ADRIANA MARIA PROCÓPIO DE ARAUJO \\ Professora Associada do Departamento de Contabilidade \\ da Faculdade de Economia, Administração e Contabilidade \\ de Ribeirão Preto da Universidade de São Paulo \\ E-mail: amprocop@usp.br
}

\section{RESUMO}

Esta pesquisa analisou a formação do professor de Contabilidade por meio de 4 áreas de formação: (i) prática; (ii) técnico-científica; (iii) pedagógica e (iv) social e política. Para isso, examinaram-se as percepções dos coordenadores dos Programas de Pós-Graduação (Stricto Sensu) na área contábil e dos discentes desses programas. Para coletar as percepções do público-alvo, utilizou-se questionário on-line, obtendo uma amostra composta por 208 discentes e 12 coordenadores. Os resultados foram identificados pela utilização de análises descritiva e de agrupamento. Foi constatado que os programas estão direcionados, em primeiro lugar, para a formação de pesquisadores com conhecimentos teóricos e específicos da área contábil, voltados para a pesquisa científica. Em segundo lugar, estão direcionados para a formação pedagógica, incentivando a docência e o desenvolvimento de habilidades didáticopedagógicas. Em terceiro lugar, segundo a opinião dos discentes, os programas têm o objetivo de incentivar a formação prática e, por último, à formação social e política, com o desenvolvimento de conhecimentos sobre política, economia, filosofia. Contudo, na opinião dos coordenadores, a ordem de importância das últimas áreas de formação está invertida, ficando em terceiro lugar a formação social e política e em quarto a formação prática.

Palavras-chave: Ensino de Contabilidade. Ensino Superior. Formação do Professor.

\section{ABSTRACT}

This research studied accounting teachers' education in four education process areas: (i) practical; (ii) technicalscientific; (iii) pedagogical and (iv) social and political. The perceptions obtained from Stricto Sensu graduate accounting programs coordinators were analyzed, as well as the perceptions obtained from accounting graduates with a master's degree (M.Sc.) and M.Sc. students, accounting graduates with a doctoral degree (Ph.D.) and Ph.D. students. An on-line questionnaire was used to collect the target public's perceptions, and the sample was composed by 208 students and 12 coordinators. The results were identified through the use of descriptive and cluster analysis. Firstly, the graduate accounting programs are directed at technical-scientific education with theoretical and specific accounting knowledge, oriented towards scientific research. Secondly, these programs aim for pedagogical education, stimulating the teachers' activities and the development of didactical-pedagogical abilities. In the third place, according to students' opinion, these programs stimulate practical education, aiming for the practical application of the theory. And, finally, these programs strongly emphasize social and political education, with knowledge development in politics, economics, philosophy and social sciences. However, according to the coordinators' opinion, the order of importance is inverted, with social and political education occupying the third and practical education the fourth place.

Keywords: Accounting Education. Higher Education. Teacher Education. 


\section{INTRODUÇÃO}

A educação está presente em todo o caminho do homem e cada indivíduo acumula experiências distintas durante sua vida, pois, desde a infância, o homem é rodeado de fatos e acontecimentos que requerem adaptações e mudanças de comportamento, é envolvido por novas experiências e novos problemas que necessitam de diferentes soluções (CORNACHIONE Jr., 2004). A educação é o suporte essencial para a formação de um cidadão, pois fornece habilidades para utilizar o conhecimento, com condições de refletir, criticar e criar.

Estudar a educação e a qualidade do ensino contribui para a promoção de mudanças e para o progresso da sociedade, principalmente nesse momento de rápida expansão dos cursos de Ciências Contábeis no país e de maior oferta de vagas para os professores dessa área. Dados da Secretaria de Ensino Superior (BRASIL, 2007), revelam que 953 Instituições de Ensino Superior (IES) estão habilitadas a oferecer o curso de ciências contábeis no Brasil, sendo 390 na região Sudeste e 206 no Estado de São Paulo. Verifica-se que o crescimento desses números acontece de forma acelerada, pois a mesma pesquisa efetuada em 2005 e 2006 já pontua o crescimento desses números. No primeiro período, verificou-se que 846 Instituições estavam habilitadas a oferecer o curso, no segundo período, 910 IES estavam habilitadas. Além desses dados, um levantamento do Censo da Educação Superior de 2004 e 2003 registrou que o curso de Ciências Contábeis está entre os dez cursos mais escolhidos pelos universitários, ficando em $7^{\circ}$ lugar em 2003 com 157.991 matrículas efetuadas e subindo para $6^{\circ}$ lugar em 2004.
Essa rápida evolução pode ser indicador de que o mercado e a sociedade estão valorizando o profissional de Contabilidade. No entanto, esse crescimento traz preocupação quanto à acessibilidade dessa educação e principalmente quanto à qualidade dos cursos, sendo assim uma das principais críticas relacionada a essa expansão. Tal fenômeno proporciona, de maneira direta e indireta, crescente interesse na base da formação do profissional contábil, ou seja, no ensino contábil, confirmando-se com o aumento das pesquisas focadas em educação. E para obter uma educação de qualidade é preciso ter professores com sólida formação, conforme afirma Cornachione (2004, p. 7): "Uma educação eficaz e de qualidade sustenta-se, de certa forma, em seu corpo docente".

O professor de Ciências Contábeis deve não só conhecer e ter domínio sobre as práticas contábeis mas também precisa conhecer a arte de ensinar. $A$ formação do docente suscita a preocupação dos pesquisadores envolvidos com a educação. Agora, não só a formação prática do professor é importante assim como a sua formação técnica por meio de conhecimentos específicos e principalmente a sua formação pedagógica.

Nesse contexto, o trabalho estuda a formação do professor de Contabilidade sob a ótica das quatro competências (aspectos da formação) do professor do ensino superior: (i) formação prática; (ii) formação técnico-científica; (iii) formação pedagógica e (iv) formação social e política. Para isso, analisou os cursos de pós-graduação (Stricto Sensu) na área de Contabilidade com o objetivo de verificar o desenvolvimento dos futuros docentes.

\section{OBJETIVOS E CONTRIBUIÇÕES DA PESOUISA}

Observando o crescimento da oferta dos cursos de graduação em Ciências Contábeis; a importância da qualificação do corpo docente e a importância que exercem na formação de profissionais (contadores), com habilidades e conhecimentos não só técnicos e específicos, mas também gerenciais e com capacidade para a tomada de decisão, verifica-se a importância em pesquisar a formação dos professores de Contabilidade.

Assim, o principal objetivo deste trabalho é verificar a importância atribuída pelos Programas de Pós-Graduação Stricto Sensu em Contabilidade para a formação prática, técnico-científica, pedagógica e social e política do professor de ensino superior de Contabilidade, junto aos discentes e coordenadores dos programas.

Este estudo proporciona benefícios práticos ao mapear e identificar a percepção dos discentes e dos coordenadores quanto ao direcionamento dos cursos de pós-graduação na área de Contabilidade oferecidos pelas Universidades no Brasil. Possui relevância social ao contribuir para a análise da qualidade do ensino e da formação de profissionais que trabalham com um instrumento indispensável para a vida das empresas e, portanto, para o mercado.

\section{REFERENCIAL TEÓRICO}

\subsection{Educação e Ensino Superior no Brasil}

A educação está presente em todo o caminho do homem e cada indivíduo acumula experiências distintas durante sua vida, pois desde a infância o homem é rodeado de fatos e acontecimentos que requerem adaptações e mu- danças de comportamento, é envolvido por novas experiências e novos problemas que necessitam de diferentes soluções (CORNACHIONE Jr., 2004). A educação é o suporte essencial para a formação de um cidadão, pois fornece habilidades para utilizar o conhecimento, com condições de refletir, criticar e criar. 
Educação [...] no lado formal, instrumenta a pessoa com a habilidade crucial de manejar a arma mais potente de combate que é o conhecimento e, no lado político, alimenta a cidadania. Sociedade educada é aquela composta de cidadãos críticos e criativos, capazes de indicar o rumo histórico, coletivamente pretendido, sobretudo desenvolver, maximamente, a oportunidade histórica disponível (DEMO, 1994, p. 47).

De acordo com Martins (2005), a educação é um processo de socialização e aprendizagem direcionada ao desenvolvimento intelectual e ético de um indivíduo. Quando esse processo de socialização e aprendizagem se dá nas escolas, denomina-se ensino.

O ensino, portanto, é tarefa predominante das instituições de ensino, que trabalham no processo de formação escolar, com alunos, professores, conhecimentos e métodos. Ensinar é "[...] formar cidadãos e cidadãs, que não estão parcelados em compartimentos estanques, em capacidades isoladas" (ZABALA, 1998, p. 28). "É reforçar a decisão de aprender e estimular o desejo de saber" (PERRENOUD, 2000, p. 71).

A educação formal brasileira está dividida em quatro níveis: (i) infantil; (ii) fundamental; (iii) médio e (iv) superior. A educação superior, foco deste trabalho, é responsabilidade do Governo Federal que fiscaliza e orienta Instituições de Ensino Superior (IES) públicas e privadas, executoras desse ensino. A finalidade do ensino superior vai além da formação do cidadão, cabe a ele a transmissão da cultura, a disseminação do conhecimento, a investigação científica, a formação de pesquisadores, o ensino de profissões e a prestação de serviços à comunidade.

Em relação ao crescimento das IES, ocorreu uma rápida expansão a partir do final da década de 90, conforme demonstram os dados do Ministério da Educação (MEC). Entre 1999 e 2004, houve uma evolução de 83,5\%, sendo que do total de 2.013 instituições, 88,9\% são instituições privadas. Verifica-se, também, que as instituições públicas cresceram $16,7 \%$ nesse período, o que significa muito para um país que pouco investe no ensino público, mas perde o significado quando comparado com o crescimento de $97,7 \%$ das instituições privadas. No entanto, deve-se salientar que "nos últimos anos vem ocorrendo uma gradual e constante diminuição no ritmo de crescimento do setor privado” (BRASIL, 2004) (Quadro 1 ( ).

Alguns fatores explicativos dessa expansão, conforme Soares (2002), são: (i) a quase universalização do ensino fundamental e o aumento das taxas de promoção e conclusão do ensino-médio; (ii) as exigências do mercado de trabalho e (iii) as vantagens sociais proporcionadas pelo diploma, ou seja, atualmente o crescimento das Instituições de Ensino Superior vem ao encontro da necessidade da sociedade e do mercado. Além disso, pode-se considerar que a criação da nova LDB (lei 9.3349 de 20/12/1996) também estimulou a expansão do ensino superior, pois autorizou a oferta de cursos seqüenciais com o intuito de servir como alternativa à rigidez dos cursos de graduação.

A expansão do ensino superior também pode ser percebida analisando a evolução dos cursos de graduação em Contabilidade, como demonstra o Gráfico 10.

\begin{tabular}{|c|c|c|c|}
\hline Ano & Públicas & Privadas & TOTAL \\
1999 & 192 & 905 & 1.097 \\
\hline 2000 & 176 & 1.004 & 1.180 \\
\hline 2001 & 183 & 1.208 & 1.391 \\
\hline 2002 & 195 & 1.442 & 1.637 \\
\hline 2003 & 207 & 1.652 & 1.859 \\
\hline 2004 & 224 & 1.789 & 2.013 \\
\hline
\end{tabular}

Fonte: Brasil (2006).

Quadro 1 - Crescimento das Instituições de Ensino Superior no Brasil de 1999 a 2004

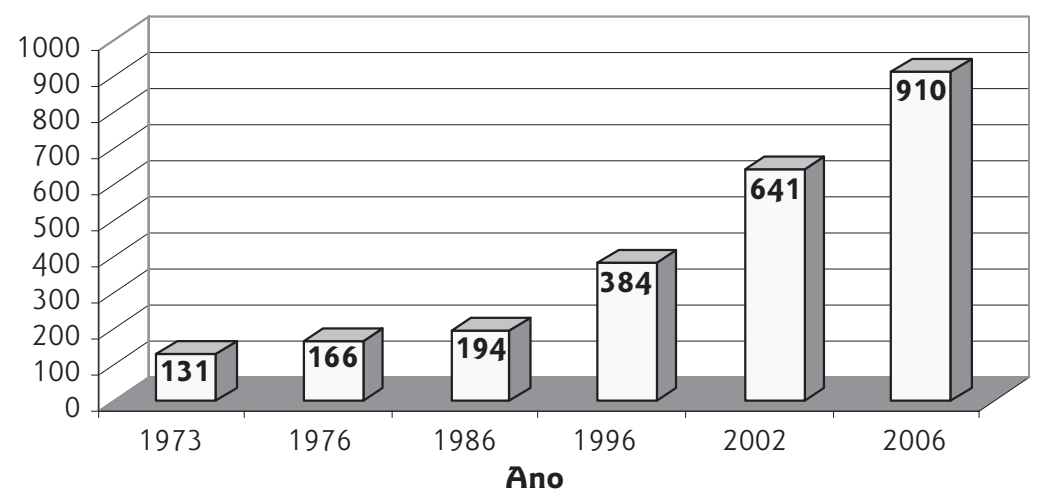

Fonte: Souza e Nascimento (2005, p. 3) e Brasil (2006).

Gráfico 1 Evolução dos Cursos de Ciências Contábeis no Brasil 
O Gráfico 1 demonstra a evolução dos cursos de Ciências Contábeis após os anos 70 , destacando a rápida expansão no número de cursos a partir da década de 90 . Analisando por períodos de 10 em 10 anos, verifica-se que de 1976 a 1986 foram criados 28 novos cursos, de 1986 a 1996 esse número cresce para 190 e de 1996 a 2006 o crescimento eleva-se para 495 novos cursos.

Essa rápida evolução demonstra que o mercado e a sociedade estão, cada vez mais, valorizando o profissional de Contabilidade. No entanto, esse crescimento traz preocupação quanto à acessibilidade dessa educação e principalmente quanto à qualidade desses cursos. Por isso, é importante que os professores de Contabilidade tenham consciência de sua importância e da sua real função como educador, assuntos esses abordados no tópico adiante.

\subsection{Orientações Conceituais na Formação dos Docentes}

O professor é a figura central, o principal capital humano de uma Instituição de Ensino Superior e, na opinião de Nassif e Hanashiro (2001, p. 100), ele é uma figura importante no sucesso ou fracasso do processo educativo. "Sobre ele recai uma grande responsabilidade quanto aos resultados esperados no que diz respeito à formação de profissionais que atuam no mercado de trabalho".

A qualidade da formação dos docentes, segundo Guerra (2003, p. 25), pode estar relacionada com as concepções sobre o papel do profissional da educação e com a concepção de ensino. "Para isso, surge como necessidade assegurar as competências intelectuais, técnica, pedagógica e política na formação dos professores". Tais competências estão relacionadas com o modelo de formação do professor apresentado por Vasconcelos (2000) (llustração 1 ( ).

i) Formação Prática: refere-se ao conhecimento da prática profissional detida pelo docente, para proporcionar ao aluno uma visão real e mais atualizada, a fim de dar um significado para o conteúdo que está sendo ensinado para a efetivação da aprendizagem. Segundo Cunha (1996), a principal estratégia utilizada para a explicação de algum conteúdo é a construção de exemplos familiares e próximos do universo dos alunos. Nesse caso, essa habilidade está muito ligada à relação teoria-prática que 0 docente possui. Vasconcelos (1994, p. 4I) coloca que: "Relacionar a teoria e prática é fator de garantia de competência para o exercício do magistério universitário", pois, o processo de ensino-aprendizagem torna-se mais fácil quando o professor possui condições de trazer para a sala de aula dados efetivos de um mundo verdadeiro, de um mercado de trabalho concreto, mais atualizado, mais coerente com a vida real. O docente com essa formação é capaz de estabelecer uma ponte entre a Academia e a sociedade, "[...] criando condições de concretizar, com maior eficiência e eficácia, a formação de seu alunado para o mundo do trabalho" (VASCONCELOS, I 994, p. 4 I). A ligação entre teoria e a prática é muitas vezes requerida pelo aluno e indispensável para a sua formação profissional. Os dois embasamentos, teórico e prático, deveriam caminhar juntos para facilitar o processo de aprendizagem. Essa formação dificilmente será adquirida pelos professores nos cursos e nas aulas de pós-graduação, no entanto, o incentivo para a aquisição desses conhecimentos deverá ser enfatizado e cobrado pela Instituição de Ensino Superior.

ii) Formação Técnico-científica: essa formação considera que o conhecimento do conteúdo especíico deve estar atrelado ao entendimento dos aspectos teóricos que cercam o assunto. O docente, segundo Zabala (1998), necessita de meios teóricos que tornem a análise da prática verdadeiramente reflexiva, entendidos como instrumentos conceituais extraídos do estudo empírico e da determinação ideológica, permitindo fundamentar a prática. Dessa forma, o professor universitário deve ser dotado de competência técnica, na área de sua especialidade, e de competência científica, voltada para a construção do novo conhecimento, entendido, neste trabalho, como a habilidade de pesquisar sua área temática, o professor-pesquisador. $\mathrm{O}$ docente deve conhecer todo o conteúdo que pretende lecionar e,

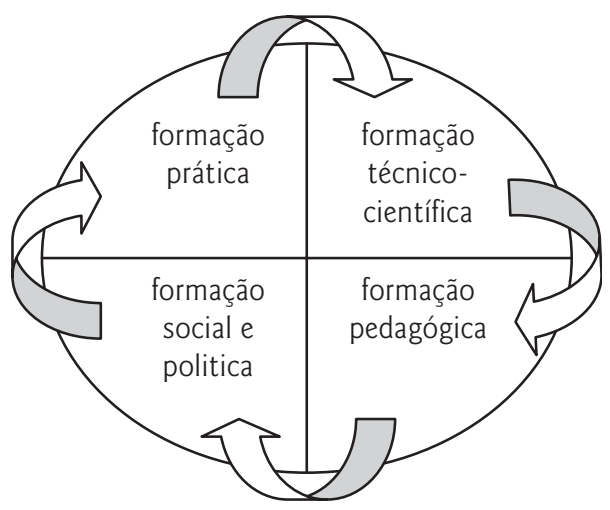

Fonte: Hernandes et al. (2006, p. 70).

Ilustração 1 || Modelo de formação do professor de Vasconcelos 
além disso, questionar, recriar, relacionar os diversos conhecimentos e estimular o aluno na busca pela pesquisa e pelo conhecimento. Vasconcelos (1 994, p. 37) coloca que: "O domínio do conteúdo específico, acompanhado da constante atualização do mesmo, é cobrança facilmente identificada no discurso tanto institucional, como discente". Possuir conhecimento e domínio do conteúdo fazem do docente uma autoridade intelectual, sendo capaz de estimular intelectualmente os alunos, fazendo progredir aqueles que possuem confiança em sua própria capacidade de trabalho (GIL, 2006).

iii) Formação Pedagógica: é importante e vai além de ministrar aulas, contempla todo o planejamento do ensino, incluindo desde os objetivos gerais da disciplina, o conhecimento dos alunos, do mercado, da avaliação da aprendizagem, das possibilidades de construção e reconstrução do conhecimento, até a relação professor-aluno. Nossa (1999a, p. 19) coloca: "Professores que nunca passaram por qualquer formação na área especificamente pedagógica certamente terão agravadas suas características de um profissional adequado para o ensino". Uma formação pedagógica consistente influencia na execução do trabalho do docente, uma vez que institui alguns conceitos e competências didáticopedagógicas essenciais. Uma delas é o saber envolver os alunos em suas aprendizagens e em seu trabalho desenvolvendo o desejo do saber, a decisão de aprender e a capacidade de auto-avaliação. Gil (2006, p. 28) esclarece que: "A habilidade de criar estímulo intelectual apresenta dois componentes: a clareza da apresentação do professor e seu impacto emocional sobre os estudantes". A clareza e o impacto emocional estão intimamente atrelados à didática do professor. A primeira relaciona-se com o que é apresentado, e a segunda com o modo pelo qual o conteúdo é passado ao aluno. Segundo Perrenoud (2000), alguns alunos têm prazer em aprender simplesmente por aprender, gostam de superar as dificuldades e os obstáculos da aprendizagem, dando mais importância ao processo do que para o resultado final. O docente deve saber trabalhar com esses alunos propondo desafios intelectuais, problemas, situações abertas e estimulantes, sem insistir nos aspectos utilitários.

iv) Formação Social e Política: Essa formação é essencial para o professor conseguir reconhecer a pessoa do aluno e visualizar o meio em que ele vive, estando preocupado com questões relacionadas ao meio social, político, ético e humano. Segundo Nossa (1999a, p. 5), "Para que o professor exerça sua cidadania num projeto de educação torna-se necessário que ele seja um intelectual crítico capaz de apreender e trabalhar as diferenças visualizadas na sala de aula [...]". A formação ética e humana do professor o torna capaz de entender e tratar com respeito as diferenças, preconceitos e discriminações de todos os gêneros. Para Perrenoud (2000, 147), "[...] não basta o docente ser contra essas diferenças, ele deve conseguir a adesão dos alunos, e para isso deve trabalhar a [...] formação que passa pelo conjunto do currículo e por uma prática - reflexiva - dos valores a incutir". Além disso, ele precisa ter uma formação social que o torne apto a dialogar com outras disciplinas como Sociologia, Filosofia, Economia e uma formação política para ser capaz de perceber as implicações sócio-culturais e políticas que ocorrem no país e no mundo. O docente universitário deve conhecer os valores éticos da carreira de seus alunos e tem o dever de retransmiti-los e, principalmente, de ser o exemplo daquilo que prega. A formação social e política garantem ao professor o conhecimento dessa necessidade e responsabilidade.

Tais competências possibilitarão fazer do docente um profissional reflexivo e, assim, atingir "[...] a condição fundamental de educador para além de instrutor, treinador, comunicador, [...] líder teórico e prático de processos construtivos de conhecimento e da cidadania" (DEMO, 1994, p. 55). Desse modo, o ideal para a formação de um docente e de um pesquisador é ter uma formação completa. Quando um curso de pós-graduação diminui a carga de cursos pedagógicos está investindo mais na formação de pesquisador do que na de um docente.

\subsection{Formação do Professor de Ciências Contábeis}

Há alguns anos, contadores e técnicos contábeis experientes, com profundos conhecimentos técnicos e legais rumavam para a carreira acadêmica com a finalidade de difundir as informações adquiridas ao longo de sua vida profissional. Atualmente, o docente de Contabilidade, além de necessitar dos conhecimentos e das habilidades da profissão contábil, necessita de conhecimentos teóricos, estruturais, didáticos e pedagógicos.

Essa formação ampla e complexa é adquirida com a experiência de mercado e com o aperfeiçoamento contínuo por meio de cursos de pós-graduação, como os de especialização e, principalmente, mestrado e doutorado. A exigência de professores com uma formação mais completa é imposta pelo mercado e, principalmente, pelas IES que seguem regras do MEC, o qual exige, segundo a Lei $n^{\circ}$ 9.394, art. 52, inciso II, pelos menos um terço do corpo docente das IES com titulação acadêmica de mestrado ou doutorado.

Além da exigência de uma titulação, o professor de Contabilidade também enfrenta outro desafio: aliar os conhecimentos teóricos e práticos, tornando o teórico tão importante quanto o prático, e o prático agradável e de fácil entendimento. Pois, quando um estudante ouve pela primeira vez as palavras 'débito', 'crédito', 'balanço' e 'razonete', tende a antipatizar com a Contabilidade se 
os seus significados e importâncias não forem compreendidos. Para isso, não basta ao docente de Contabilidade ter o domínio da prática contábil, ele deve conhecer a teoria e o embasamento dos métodos e dos sistemas utilizados.

O trabalho apresentado por Nossa (1999a) enumera algumas das deficiências no ensino de Contabilidade. $\mathrm{Na}$ década de 80, essas deficiências eram causadas por carência de bons profissionais, falta de preparo do corpo docente, falhas nas metodologias de ensino aplicadas, falta de integração entre os professores, falta de adequação do currículo e de programas bem definidos sobre a prática contábil.

Na década de 90, fazendo referência ao trabalho de Schmidt, Nossa (1999a, p. 41) destaca que "[...] uma das maiores deficiências na educação contábil no Brasil é a falta de treinamento para os professores dos cursos de Ciências Contábeis". Aponta para o baixo número de docentes com cursos de Mestrado e Doutorado e relaciona as instituições que possuem a maioria dos docentes em formação inicial (menos de cinco anos na atividade de ensino) com o baixo desempenho dos alunos.

Além dessas deficiências, o autor (NOSSA, 1999b), ao investigar as causas do baixo desempenho acadêmico dos professores de Ciências Contábeis, também constatou os seguintes motivos:

i. expansão extraordinária dos cursos: o rápido crescimento do número de cursos na área de Contabilidade exigiu a contratação de professores com pouca experiência acadêmica, na maioria profissionais oriundos do setor empresarial;

ii. falta de investimento por parte das Instituições: a maioria das IES particulares estão interessadas na lucratividade, investindo apenas o mínimo necessário para atingir seus objetivos;

iii. maior atração por parte do mercado profissional e falta de incentivo à carreira acadêmica: baixa remuneração e falta de um plano de carreira leva para o mercado de trabalho pessoas que poderiam atuar no magistério; iv. reduzido número de cursos de mestrado e doutorado, falta de pesquisa e pouco conhecimento em cultura geral: "pequeno número de cursos Stricto Sensu em Contabilidade, a falta de cultura geral e humanística e a falta de tempo para a pesquisa leva a maioria dos professores a aceitar coisas como verdades absolutas, sem discuti-las" (NOSSA, 1999b, p. 14).

Com relação aos motivos apontados por Nossa, alguns deles estão sendo minimizados, como é o caso da expansão dos cursos de graduação e do número de cursos de mestrado e doutorado. No primeiro semestre de 2007, doze Programas de Pós-Graduação (doze de mestrado e dois ${ }^{1}$ de doutorado) estavam efetivamente habilitados para formar professores e pesquisadores, oito programas a mais do que aqueles existentes em 1999. Dessa forma, o número de mestres, principalmente, aumentou, gerando uma disponibilidade maior de profissionais habilitados para a área do ensino. Contudo, um dos fatores que este trabalho objetiva verificar é a formação desses professores em relação aos conhecimentos didático-pedagógicos e técnico-científicos citados por Nossa como uma deficiência não verificada no momento da contratação do docente pela IES.

Outras deficiências também podem ser destacadas como: a falta de conhecimento prático prejudicando a explanação e a exemplificação de problemas contábeis, principalmente aqueles relacionados a temas técnicos e específicos, como é o caso de perícia contábil, contabilidade governamental, auditoria, entre outros; e a falta de conhecimento social e político, afetando discussões relacionadas aos problemas do país, da economia, da ética empresarial, da ética profissional.

Essa discussão demonstra a importância do aprimoramento e treinamento do professor de Contabilidade, que pode ser obtido por meio de experiências no mercado, pesquisas, investigação e, principalmente, através dos cursos de pós-graduação.

\section{ASPECTOS METODOLÓGICOS}

Para verificar se o docente de Contabilidade contempla a formação ideal, analisaram-se os programas de mestrado e doutorado em Contabilidade por meio da percepção dos discentes e coordenadores desses programas.

Segundo Gil (2002, p. 42), as pesquisas que possuem como objetivo principal a descrição das características de determinado fenômeno ou população, ou que estabelecem relações entre variáveis podem ser denominadas de pesquisas descritivas. Como o objetivo principal deste trabalho é verificar a relevância das áreas de formação do professor de Ciências Contábeis, pode-se defini-lo como descritivo.
Como também proporciona uma familiaridade maior com o problema, tornando-o mais claro, aproxima-se da pesquisa exploratória. Assim, o tipo de pesquisa considerada é a pesquisa descritiva com característica exploratória.

Para coletar as percepções do público-alvo, utilizou-se questionário on-line, obtendo-se uma amostra composta por 208 discentes e 12 coordenadores, representantes dos Programas de Pós-Graduação da FUCAPE, FURB, PUC/SP, UFC, UFPR, UFRJ, UFSC, UNB'2, UFPB, UFPE, UFRN, FECAP, UNISINOS, USP/RP e USP. Dois questionários foram aplicados, um direcionado aos mestrandos, mestres,

\footnotetext{
1 O programa de doutorado da UNB foi homologado pelo CNE em dezembro de 2006

2 É importante esclarecer que a UNB atua, até 2007, em conjunto com a UFPB, UFPE e UFRN com o programa denominado Multi-institucional.
} 
doutorandos e doutores em Contabilidade, denominados genericamente de "discentes", e outro orientado aos coordenadores dos Programas de Pós-Graduação Stricto Sensu na área contábil. Por meio desse instrumento, buscou-se identificar a percepção dos discentes e coordenadores sobre o programa, medida por meio da escala Likert, mensurada de 1 (discordância total) a 5 (concordância total).

Neste estudo, trabalhou-se com 16 variáveis, denominadas ao longo do trabalho de afirmações, formuladas de acordo com a fundamentação teórica, com a finalidade de medir a importância dada pelos programas para as áreas de formação do professor.

Dessa forma, para a formação prática foram estabelecidas três afirmações: Q1 - durante o processo de seleção, as minhas experiências profissionais (junto ao mercado) foram decisivas para a aprovação no programa; Q9 - o programa está estruturado na preparação de profissionais para o mercado; Q10 - os docentes de pós-graduação devem possuir experiências de mercado.

Para a formação técnico-científica formularam-se quatro afirmações: Q2 - durante o processo de seleção, os meus conhecimentos acadêmicos e minhas publicações foram importantes para a aprovação no programa; Q5 - o Programa de Pós-Graduação está estruturado na preparação de pesquisadores; Q12 - a disciplina de metodologia de pesquisa científica é importante na grade do programa; Q16 - o programa incentiva financeiramente a participação em simpósios e congressos.

Cinco afirmações foram estabelecidas para medir a formação pedagógica, sendo elas: Q3 - durante o processo de seleção, a minha experiência na área de ensino foi relevante para a aprovação no programa; Q6 - o programa está estruturado na preparação do professor de ensino superior; Q7 - a disciplina de metodologia do ensino é importante na grade curricular; Q8 - o programa incentiva os alunos a iniciarem atividades docentes durante o curso; Q14 - o programa incentiva o aperfeiçoamento no ensino com orientação docente.

Por fim, quatro afirmações foram utilizadas para analisar a formação social e política: Q4 - durante o processo de seleção, a minha atuação na área social e política (movimento estudantil, trabalho voluntário, atividades de extensão, entre outros) foi importante para a aprovação no programa; Q11 - o Programa de Pós-Graduação está estruturado na preparação de profissionais com conhecimentos multidisciplinares (como Sociologia, Economia, Filosofia, Ciências Políticas etc.); Q13 - informações sobre a conjuntura política, econômica e social devem fazer parte dos conteúdos das disciplinas; Q15 - para a formação do docente é importante que o programa ofereça disciplinas de economia, filosofia, sociologia e ciências políticas.

As 16 afirmações, especificadas para cada área de formação, abordaram os seguintes tópicos: (i) processo de seleção; (ii) estruturação do programa; (iii) importância da(s) disciplina(s); (iv) incentivo à docência e ao estágio; (v) docente com experiência no mercado; (vi) formação do professor; (vii) participação em congressos, eventos acadêmicos.

Dos questionários coletados obtiveram-se dados em escala ordinal e intervalar, sendo utilizadas as técnicas estatísticas descritivas e multivariadas para tratar as variáveis. As técnicas descritivas foram utilizadas para traçar o perfil da amostra, identificar os direcionamentos dos programas e os tipos de formação do professor prevalecentes e as técnicas multivariadas para caracterizar os grupos de respondentes.

Das técnicas multivariadas trabalhou-se com a análise de agrupamentos (cluster) que, segundo Malhotra (2006, p. 572), "[...] estuda todo um conjunto de relações interdependentes", identificando as semelhanças entre as observações. Para mensurar e analisar os dados, utilizou-se o software SPSS ${ }^{\circledR}$ e o programa Excel ${ }^{\circledR}$ da Microsoft.

\section{ANÁLISE E INTERPRETAC̣ÃO DOS DADOS}

A amostra discente, em síntese, é composta por respondentes de 15 IES membros de 12 Programas de Pós-Graduação. Possuem, entre 20 e 40 anos, na maioria representantes do sexo masculino, graduados em Ciências Contábeis, ainda cursando o Programa de Pós-Graduação, apresentando um intervalo aproximado de 4 anos entre a conclusão do curso de graduação e o início do mestrado e doutorado.

A região Sudeste concentra 39\% dos programas pesquisados, sendo identificados com as seguintes instituições de ensino superior: FUCAPE, FURB, UFRJ, FECAP, USP e USP/RP. A região Sul agrupa $27 \%$ dos programas pesquisados, estando vinculados a FURB, UFPR, UFSC e UNISINOS. No Centro-Oeste, tem-se como representante a UNB, e a concentração de $27 \%$ no Nordeste está distribuída entre a UFC, UFPB, UFPE, UFRN.

$A$ amostra docente é composta por 12 coordenadores ou vice-coordenadores que respondem pelo Programa de
Pós-Graduação da Instituição. Dentre os respondentes encontram-se 10 doutores em Controladoria e Contabilidade, representando 83,33\% da amostra, 1 doutor em Economia e 1 doutor em Administração de Empresas.

Ao se trabalhar com escala, torna-se necessário medir sua confiabilidade. Malhotra (2006) esclarece que a confiabilidade mostra até que ponto uma escala produz resultados consistentes, indicando baixa confiabilidade quando apresentar erros aleatórios. Hair Jr. et al. (2005) acrescentam que o alfa de Cronbach é a medida de confiabilidade mais amplamente utilizada, tendo seu limite inferior aceito entre 0,60 e 0,70, apresentando uma relação positiva com o número de itens da escala, sendo aplicado neste trabaIho. A confiabilidade da escala foi 0,7274 indicando consistência interna estatisticamente satisfatória.

A Tabela $1 \oslash$ contempla somente os percentuais de concordância e discordância para as afirmações, cuja le- 
Tabela 1 || Relação de concordância e discordância entre discentes e coordenadores

\begin{tabular}{|c|c|c|c|c|c|}
\hline & & \multirow{2}{*}{\multicolumn{2}{|c|}{$\begin{array}{c}\text { Discentes } \\
\text { Médias }\end{array}$}} & \multicolumn{2}{|c|}{ Coordenadores } \\
\hline & & & & & \\
\hline & & Concordo & Discordo & Concordo & Discordo \\
\hline \multirow{3}{*}{ 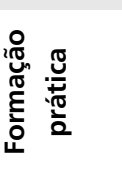 } & Q1 & $49 \%$ & $26 \%$ & $33 \%$ & $17 \%$ \\
\hline & Q9 & $57 \%$ & $22 \%$ & $58 \%$ & $17 \%$ \\
\hline & Q10 & $73 \%$ & $8 \%$ & $67 \%$ & $8 \%$ \\
\hline \multirow{4}{*}{ 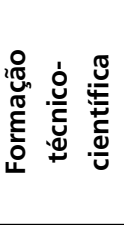 } & Q2 & $67 \%$ & $14 \%$ & $100 \%$ & $0 \%$ \\
\hline & Q5 & $89 \%$ & $7 \%$ & $100 \%$ & $0 \%$ \\
\hline & Q12 & $97 \%$ & $0 \%$ & $100 \%$ & $0 \%$ \\
\hline & Q16 & $46 \%$ & $36 \%$ & $83 \%$ & $17 \%$ \\
\hline \multirow{5}{*}{ 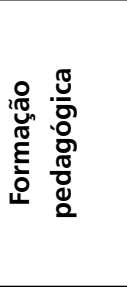 } & Q3 & $43 \%$ & $31 \%$ & $100 \%$ & $0 \%$ \\
\hline & Q6 & $74 \%$ & $15 \%$ & $75 \%$ & $8 \%$ \\
\hline & Q7 & $92 \%$ & $2 \%$ & $83 \%$ & $8 \%$ \\
\hline & Q8 & $60 \%$ & $19 \%$ & $91 \%$ & $0 \%$ \\
\hline & Q14 & $65 \%$ & $11 \%$ & $83 \%$ & $0 \%$ \\
\hline \multirow{4}{*}{ 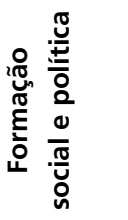 } & Q4 & $9 \%$ & $57 \%$ & $8 \%$ & $16 \%$ \\
\hline & Q11 & $37 \%$ & $39 \%$ & $67 \%$ & $25 \%$ \\
\hline & Q13 & $85 \%$ & $5 \%$ & $83 \%$ & $0 \%$ \\
\hline & Q15 & $62 \%$ & $12 \%$ & $67 \%$ & $25 \%$ \\
\hline
\end{tabular}

genda encontra-se no apêndice, excluindo os percentuais de respostas indiferentes, segundo as percepções dos discentes e, também, dos coordenadores.

Analisando a formação prática, em relação a Q1, 49\% dos discentes acreditam que suas experiências profissionais foram relevantes para a aprovação no Programa de Pós-Graduação, contra $26 \%$ da amostra que percebeu como pouco decisivo os seus conhecimentos profissionais durante 0 processo seletivo. Metade da amostra dos coordenadores é indiferente à afirmação (Q1) e 17\% discordam. Isso indica que, para eles, a experiência profissional do ingressante não influencia no processo de aprovação no programa.

Ao estudar as opiniões dos respondentes quanto à estruturação dos programas para a formação de profissionais voltados ao mercado(Q9), verifica-se um baixo grau de concordância, pois, segundo os dados da Tabela 1, 57\% dos discentes e $58 \%$ dos coordenadores concordam com a afirmação. Pela Tabela 1, verifica-se a importância dada pelos discentes quanto à necessidade de os professores de pós-graduação possuírem experiência de mercado (Q10). Essa importância também é confirmada pelos coordenadores. Do total de respondentes, $73 \%$ dos discentes e $67 \%$ dos coordenadores concordam com a afirmação Q10. Entre as respostas discordantes, encontram-se $8 \%$ dos discentes e $8 \%$ dos coordenadores.

Analisando a formação técnico-científica e considerando as percepções dos discentes sobre a importância das publicações e das atividades acadêmicas em relação à aprovação no Programa de Pós-Graduação Stricto Sensu (Q2), pôde-se identificar um grau de concordância de 67\% entre os respondentes discentes, conforme disponibilizado na Tabela 1. Ao contrário dos discentes, 100\% dos coordenadores responderam favoravelmente à Q2. De acordo com suas percepções, as publicações e os conhecimentos acadêmicos são pontos chaves para o processo de aprovação de um candidato ao Programa de Pós-Graduação em Ciências Contábeis, identificando a importância dada para a formação técnico-científica.

Com relação aos Programas de Pós-Graduação estarem estruturados para a preparação de pesquisadores (Q5), é quase unânime a concordância dos respondentes discentes e coordenadores, identificando uma direção totalmente favorável ao incentivo de pesquisas e atividades acadêmicas voltadas para a formação na área técnico-científica.

Quanto à importância do oferecimento da disciplina de metodologia de pesquisa científica nas grades dos programas (Q12), não houve discordância entre as opiniões dos discentes e as dos coordenadores. Para $70 \%$ dos mestres, mestrandos, doutores e doutorandos, está totalmente clara a relevância de uma disciplina focada para o aprendizado de metodologias científicas. Essa mesma direção é seguida por $92 \%$ dos coordenadores.

Além dos incentivos internos à formação técnico-científica, é interessante conhecer a percepção dos respondentes quanto aos incentivos financeiros oriundos dos programas para a participação em simpósios e congressos (Q16). 
Nesse item, 36\% dos respondentes discentes indicaram que o incentivo financeiro para esses eventos não é uma prática usual dos programas, enquanto $83 \%$ dos coordenadores afirmaram a existência desse incentivo.

Em relação à formação pedagógica, verificando a importância estabelecida pelos programas durante o processo de seleção (Q3), 43\% dos respondentes discentes pontuaram-na como relevante ou altamente relevante. Analisando as percepções dos coordenadores para a mesma afirmação (Q3), nota-se a concentração de respostas nos conceitos concordo e concordo totalmente. Esse nível de importância não é tão evidente para os alunos, que apresentaram um grau de discordância de 31\%.

Tratando-se da estruturação dos programas (Q6), 74\% dos discentes percebem que estão direcionados para a formação didático-pedagógica, focando a formação do professor de ensino superior. Essa percepção é confirmada por $75 \%$ dos coordenadores. Outro fator observado na Tabela 1 é o alto nível de concordância entre os grupos sobre a importância da disponibilização de disciplinas voltadas para a educação e para o ensino. Dos discentes, $92 \%$ apresentaram respostas favoráveis a Q7, dos coordenadores 83\% compartilham da mesma opinião.

Quanto aos programas incentivarem os alunos a iniciarem atividades docentes durante o curso (Q8), 31\% dos discentes e $58 \%$ dos coordenadores pesquisados concordam com a afirmação, porém não tanto quanto os $29 \%$ discentes e 33\% coordenadores que concordam totalmente. Os discentes não possuem uma visão tão favorável quanto a dos coordenadores, pois apresentam 19\% de discordância em relação à Q8, demonstrando que esse incentivo não é amplamente divulgado dentro dos cursos.

O fomento aos estágios supervisionados na área de ensino (Q14) pode ser visualizado na Tabela 1, porém em menor proporção do que 0 incentivo às atividades docentes propriamente ditas, como lecionar, preparar e monitorar aulas em IES. Na visão de $83 \%$ dos coordenadores, os programas costumam incentivar o aperfeiçoamento no ensino com orientação docente, porém para $34 \%$ dos alunos, em alguns programas, essa forma de estágio não é proporcionada ou não é divulgada.
Estudando a formação social e política, pela Tabela 1 observam-se as percepções dos discentes e as dos coordenadores com relação à importância que os programas deram às experiências e vivências dos candidatos durante o processo de seleção (Q4). Verifica-se que as atuações na área social e política não são relevantes. Ao estudar as percepções dos coordenadores, $75 \%$ não adotam opiniões favoráveis nem contrárias à atuação do candidato na área social e política, sendo indiferente para a aprovação nos programas de pós-graduação em Ciências Contábeis. Porém, 57\% dos discentes adotam opiniões desfavoráveis, acreditando que os programas não dão importância a essas experiências durante a seleção.

Apesar de os coordenadores apresentarem opiniões indiferentes em relação ao processo seletivo, $67 \%$ deles concordam, mas não totalmente, que os programas estão estruturados para a preparação de profissionais com conhecimentos multidisciplinares (Q11). Essa visão não é confirmada pelos discentes que apresentam somente 37\% das respostas concordantes. Vale ressaltar a concordância dos dois grupos quanto à importância de informações da área social e política fazerem parte dos conteúdos das disciplinas oferecidas pelos Programas de Pós-Graduação. Da amostra discentes, 85\% concordam com Q13 da amostra coordenadores, $83 \%$ concordam.

Porém, em se tratando da formação do professor, $25 \%$ dos coordenadores acreditam que não é importante o programa oferecer disciplinas como Sociologia, Filosofia E Ciências Sociais, 12\% dos discentes também seguem esse pensamento. Apesar dessas respostas discordantes, a maioria dos coordenadores e dos discentes, 67\% e 62\% respectivamente, concordam com a afirmação Q15.

Analisando somente a amostra discente e por meio da técnica de agrupamento (cluster), foi possível identificar dois grupos de respondentes bem definidos: os de perfil concordante com médias mais altas e os de perfil discordante com médias mais baixas.

A Tabela 20 agrupa as médias de respostas concordantes e discordantes para todas as áreas de formação, facilitando a identificação das áreas com maior e menor importância, conforme a visão dos mestres, mestrandos, doutores e doutorandos da área Contábil.

Tabela 2 Relação de importância das áreas de formação para os discentes

\begin{tabular}{l|c|c}
\hline \multicolumn{3}{c}{ Concordantes } \\
\hline Áreas de formação & N & Média \\
\hline $1^{\circ}$ Formação técnico-científica & 90 & 4,41 \\
\hline $2^{\circ}$ Formação pedagógica & 83 & 4,38 \\
\hline $3^{\circ}$ Formação prática & 118 & 4,03 \\
\hline $4^{\circ}$ Formação social e política & 83 & 3,62 \\
\hline \multicolumn{3}{c}{ Discordantes } \\
\hline Áreas de formação & $\mathbf{N}$ & Média \\
\hline $1^{\circ}$ Formação técnico-científica & 117 & 3,55 \\
\hline $2^{\circ}$ Formação pedagógica & 125 & 3,35 \\
\hline $3^{\circ}$ Formação social e política & 123 & 3,03 \\
\hline $4^{\circ}$ Formação prática & 90 & 2,94 \\
\hline \multicolumn{3}{|c|}{}
\end{tabular}


$A$ formação técnico-científica é a que apresenta maior relevância, com 90 respondentes concordantes convictos que é a área mais incentivada pelos programas. Essa área, mesmo entre os respondentes discordantes, recebeu o maior número de respostas favoráveis. A formação pedagógica aparece em segundo lugar por ordem de importância. A média de respostas dos 83 respondentes concordantes foi 4,38, indicando a preocupação do programa com essa área de formação. Entre os respondentes discordantes, a média foi de 3,35, sendo a segunda média mais alta entre as áreas de formação pesquisada.

Pela análise do agrupamento concordante, a formação prática ficaria em terceiro lugar, com 118 discentes apresentando opiniões favoráveis. Em último lugar, estaria a formação social e política com média 3,62. Contudo, analisando o agrupamento discordante, a ordem de importância entre as duas áreas se inverte, com a formação social e política apresentando média superior à apresentada pela formação prática.

\section{CONSIDERAÇÕES FINAIS}

Com o estudo realizado, foi possível identificar as características da formação dos professores de Contabilidade e verificar, dentro das limitações que se apresentaram, a importância atribuída pelos Programas de Pós-Graduação Stricto Sensu em Contabilidade para a formação prática, técnico-científica, pedagógica e social e política do professor de ensino superior de Contabilidade, junto aos discentes e coordenadores dos programas.

Como visto, é importante que o professor de ensino superior em Contabilidade possua uma formação completa, englobando a formação prática, com conhecimentos da prática profissional, de mercado; a formação técnico-científica, sendo detentor de conceitos teóricos e específicos com experiência em pesquisas acadêmicas; conhecimentos didáticos, advindos de experiências adquiridas com a docência ou do aperfeiçoamento pedagógico por meio de cursos e aulas; conhecimentos sociais e políticos, possibilitando a discussão de assuntos econômicos, políticos e sociais envolvendo o país e a própria profissão.

Na opinião dos discentes e coordenadores dos Programas de Pós-Graduação Stricto Sensu na área Contábil, os programas estão altamente direcionados para a formação técnico-científica, para a formação de pesquisadores. A relevância da formação técnico-científica é justificada: (i) pela importância percebida pelos discentes e coordenadores, das publicações científicas e atividades de pesquisa para a escolha dos candidatos; (ii) pela estruturação do programa voltado para a pesquisa; (iii) pelo incentivo das atividades de desenvolvimento de pesquisa, como publicação de artigos em periódicos, anais e participação em congressos e simpósios. Vale ressaltar a relevância percebida por $97 \%$ dos discentes e por $100 \%$ dos coordenadores quanto ao oferecimento de disciplinas focadas no aprendizado de metodologias científicas para a completa formação do docente de ensino superior em Contabilidade.

Em segundo lugar, os programas apresentam um direcionamento à formação pedagógica. Esse direcionamento é enfatizado: (i) pela forma como o programa está estruturado; (ii) pelos incentivos ao início das práticas docentes; (iii) pelo oferecimento de aperfeiçoamento no ensino com a orientação docente (estágios supervisionados); (iv) e respaldado pela evolução dos conhecimentos pedagógicos adquiridos pelos discentes. Em relação ao oferecimento de disciplinas voltadas para área de ensino,
$92 \%$ dos discentes e $83 \%$ dos coordenadores, confirmam a necessidade e a importância de seus conteúdos para a formação do professor de Ciências Contábeis.

O incentivo dos programas à formação prática é apresentado, segundo a visão discente, em terceiro lugar, pois: (i) não identificaram claramente uma posição favorável ou desfavorável quanto à importância de suas experiências profissionais durante o processo de seleção; (ii) $57 \%$ afirmaram que o programa está estruturado para a formação prática, enquanto $42 \%$ discordaram ou não conseguiram identificar esse direcionamento; (iii) identificaram como relevante o fato de os docentes de pós-graduação possuírem conhecimentos de mercado. Entretanto, segundo a percepção dos coordenadores, essa formação é a que apresenta menor importância para os programas. A divergência entre as percepções discentes e as dos coordenadores está relacionada com a importância das experiências de mercado do candidato durante o processo seletivo, pois somente 33\% dos coordenadores apresentam respostas concordantes, contra $49 \%$ dos discentes. E em relação aos docentes dos Programas de Pós-Graduação possuírem experiências de mercado, $67 \%$ dos coordenadores apresentaram respostas concordantes, contra $73 \%$ dos discentes.

A formação social e política é caracterizada, na visão discente, como a menos incentivada pelos Programas de PósGraduação e, na visão dos coordenadores, como a terceira mais incentivada. A pouca relevância apresentada pelos programas é embasada nas seguintes interpretações: (i) $91 \%$ dos discentes percebem que os programas não consideram como fundamental para o ingresso na pós-graduação, as experiências sociais e políticas vivenciadas por eles, ao contrário dos $75 \%$ dos coordenadores que se mostram indiferentes à afirmação; (ii) não estruturação dos cursos para a preparação de profissionais com conhecimentos nessa área, confirmada por $62 \%$ dos discentes e somente por 33\% dos coordenadores. Apesar da heterogeneidade das respostas entre as amostras discentes e coordenadores, cabe ressaltar que o reconhecimento da importância da área social e política na formação do professor é expressa pelos dois grupos.

Assim, identificou-se um desencontro de percepções entre os discentes e os coordenadores, demonstrando que as expectativas dos discentes nem sempre são identificadas pelos programas. Outro fator apontado foi a pequena distinção entre os objetivos do mestrado e do doutorado. 
O mestrado tem como objetivo a formação do docente e o doutorado a formação do pesquisador, porém constatouse que os programas de mestrados estão mais direcionados para a formação técnico-científica.

De acordo com as percepções dos discentes e dos coordenadores pesquisados, verificou-se que o professor de ensino superior em Contabilidade, capacitado ao exercício dessa função pelo título defendido em um Programa de Pós-Graduação na área Contábil, possui uma formação voltada, principalmente, para a pesquisa científica, com conhecimentos da área pedagógica. Contudo, para que o professor de Contabilidade tenha uma formação completa, é necessário que os programas se preocupem mais com a formação prática, desenvolvendo a capacidade da aplicação da teoria na prática. E, por fim, os programas deveriam inserir, em sua estrutura, atividades, conteúdos ou disciplinas, que aprimorem os conhecimentos sociais e políticos dos mestrandos e doutorandos, proporcionando condições de entendimento do mundo e da participação dentro dele.

\section{Referências}

BRASIL. Ministério da Educação. Instituto Nacional de estudos e Pesquisas Educacionais. INEP. Censo de Educação Superior 2004 - Resumo Técnico. Disponível em: <http://www.mec.gov.br>. Acesso em: 27 jan. 2006.

BRASIL. Ministério da Educação. Instituto Nacional de estudos e Pesquisas Educacionais. INEP. Censo de Educação Superior. 2006. Disponível em: $<$ http://www.educacaosuperior.inep.gov.br $>$. Acesso em: 27 dez. 2006.

BRASIL. Ministério da Educação. Instituto Nacional de estudos e Pesquisas Educacionais. INEP. Cadastro das Instituições de Ensino Superior. 2007. Disponível em: <http://www.educacaosuperior.inep.gov.br>. Acesso em: 22 jan. 2007.

CORNACHIONE JR. E. B. Tecnologia da educação e cursos de ciências contábeis: modelos colaborativos virtuais. 2004. Tese (Livre - docência) - Faculdade de Economia, Administração e Contabilidade, Universidade de São Paulo, São Paulo.

CUNHA, M. I. O bom professor e sua prática. 6. ed. Campinas: Papirus, 1996.

DEMO, P. Educação e qualidade. Papirus, 1994.

GIL, A. C. Como elaborar projetos de pesquisa. 4. ed. São Paulo: Atlas, 2002

Didática do ensino superior. São Paulo: Atlas, 2006.

GUERRA, C. T. O ensino de psicologia na formação inicial de professores: constituição de conhecimentos sobre aprendizagem e .

desenvolvimento por estudantes de licenciatura. 2003. Tese (Doutorado em Educação) - Faculdade de Educação, Universidade Estadual de Campinas, Campinas.

HAIR. Jr. J. F. et al. Análise multivariada de dados. 5. ed. São Paulo: Bookman, 2005.

HERNANDES, D. C. R. et al. O professor de contabilidade: habilidades e competências. In: PELEIAS, I. R. (Org.). Didática do ensino superior da contabilidade: aplicável a outros cursos superiores. São Paulo: Saraiva, 2006. p. 61-119.

MALHOTRA, N. K. Pesquisa de marketing: uma orientação aplicada. 4. ed. Porto Alegre: Bookman, 2006.

MARTINS, V. Constituição de 1988 e seu artigo 206: ensino e educação, 2005. Disponível em: <http://www.eduquenet.net/ensinoeducacao. htm>. Acesso em: 01 fev. 2006.

NASSIF, V. M. J.; HANASHIRO, D. M. M. A competitividade das universidades particulares à luz de uma visão baseada em recursos. Revista de Administração Mackenzie, São Paulo, v. 3, n. 1, p. 95-114, 2001.

NOSSA, V. Ensino da contabilidade no Brasil: uma análise crítica da formação do corpo docente. 1999. Dissertação (Mestrado em Ciências Contábeis) - Faculdade de Economia, Administração e Contabilidade, Universidade de São Paulo, São Paulo, 1999a.

Formação do corpo docente dos cursos de graduação em contabilidade no Brasil: uma análise crítica. Caderno de Estudos da Fipecafi, São Paulo, v. 11, n. 21, p. 74-92, maio/ago. 1999b.

PERRENOUD, P. Formando professores profissionais: quais estratégias? quais competências. Porto Alegre: Artmed, 2000 .

SOUZA, M. A.; NASCIMENTO, C. L. Qualidade do ensino superior de ciências contábeis: um diagnóstico nas instituições localizadas na região norte do estado do Paraná. In: ENCONTRO DA ASSOCIAÇÃO NACIONAL DE PÓS-GRADUAÇÃO E PESQUISA EM ADMINISTRAÇÃO, 13., 2005, Brasília, Anais... Brasília, 2005.

VASCONCELOS, M. L. M. C. O profissional liberal na docência de $3^{\circ}$ grau: uma proposta de atualização pedagógica. 1994. Tese (Doutorado em Administração) - Universidade Mackenzie, São Paulo.

A formação do professor do ensino superior. 2. ed. São Paulo: Pioneira, 2000.

ZABALA, A. A prática educativa: como ensinar. Porto Alegre: Artmed, 1998.

\section{NOTA - Endereço dos autores}

Faculdades Integradas Fafibe

Rua Prof. Orlando França de Carvalho, 325 - Centro

Bebedouro - SP

$14701-070$
Universidade de São Paulo

Faculdade de Economia, Administração e Contabilidade de Ribeirão Preto

Departamento de Contabilidade

Av. dos Bandeirantes, 3900 - Monte Alegre

Ribeirão Preto - SP

14040-900 


\section{APÊNDICE}

\section{LEGENDA}

Q1. Durante o processo de seleção, as minhas experiências profissionais (junto ao mercado) foram decisivas para a aprovação no programa.

Q2. Durante o processo de seleção, os meus conhecimentos acadêmicos e minhas publicações foram importantes para a aprovação no programa.

Q3. Durante o processo de seleção, a minha experiência na área de ensino foi relevante para a aprovação no programa.

Q4. Durante o processo de seleção, a minha atuação na área social e política (movimento estudantil, trabalho voluntário, atividades de extensão, entre outros) foi importante para a aprovação no programa.

Q5. O Programa de Pós-Graduação está estruturado na preparação de pesquisadores.

Q6. O programa está estruturado na preparação do professor do ensino superior.

Q7. A disciplina de metodologia do ensino é importante na grade curricular.

Q8. O programa incentiva os alunos a iniciarem atividades docentes durante o curso.

Q9. O programa está estruturado na preparação de profissionais para o mercado.

Q10. Os docentes dos Programas de Pós-Graduação devem possuir experiência de mercado.

Q11. O programa está estruturado na preparação de profissionais com conhecimentos multidisciplinares (como Sociologia, Economia, Filosofia, Ciências Políticas etc.).

Q12. A disciplina de Metodologia de Pesquisa Científica é importante na grade do programa.

Q13. Informações sobre a conjuntura política, econômica e social devem fazer parte dos conteúdos das disciplinas.

Q14. O programa incentiva o aperfeiçoamento no ensino com orientação docente.

Q15. Para a formação do docente é importante que o programa ofereça disciplinas de Economia, Filosofia, Sociologia e Ciências Políticas.

Q16. O programa incentiva financeiramente a participação em simpósios e congressos. 